\title{
Smart Metal-Organic Framework Coatings: Triggered Antibiofilm Compound Release
}

\author{
Birgit Claes, ${ }^{\ddagger} \dagger \odot$ Tom Boudewijns, ${ }^{\ddagger}$ Laurens Muchez, ${ }^{\ddagger \dagger}$ Geert Hooyberghs, ${ }^{\S}$ Erik V. Van der Eycken, ${ }^{\S}$ \\ Jozef Vanderleyden, ${ }^{\mathbb{T}}$ Hans P. Steenackers, ${ }^{\text {II }}$ and Dirk E. De Vos ${ }^{*,+, \dagger}$ \\ ${ }^{\ddagger}$ Centre for Surface Chemistry and Catalysis, KU Leuven, Kasteelpark Arenberg 23, 3001 Leuven, Belgium \\ ${ }^{\S}$ Molecular Design and Synthesis, KU Leuven, Celestijnenlaan 200F, 3001 Leuven, Belgium \\ ${ }^{\mathrm{II}}$ Centre for Microbial and Plant Genetics, KU Leuven, Kasteelpark Arenberg 20, 3001 Leuven, Belgium
}

Supporting Information

ABSTRACT: Metal-organic frameworks (MOFs) have a large potential for delivery of active molecules. Here, a MOF coating is investigated as a smart host matrix for triggered release of antibiofilm compounds. In addition to a coating consisting of the regular Fe-terephthalate MIL- $88 \mathrm{~B}(\mathrm{Fe})$, a new hydrophobic MIL-88B $(\mathrm{Fe})$ coating is synthesized in hydrothermal conditions using palmitic acid as a lattice terminating group. These porous materials are used as a host matrix for the antibiofilm compound 5-(4-chlorophenyl)- $\mathrm{N}$-(2-isobutyl)-2aminoimidazole, which has a specific biofilm-inhibiting effect at concentrations at which no activity against planktonic cells is

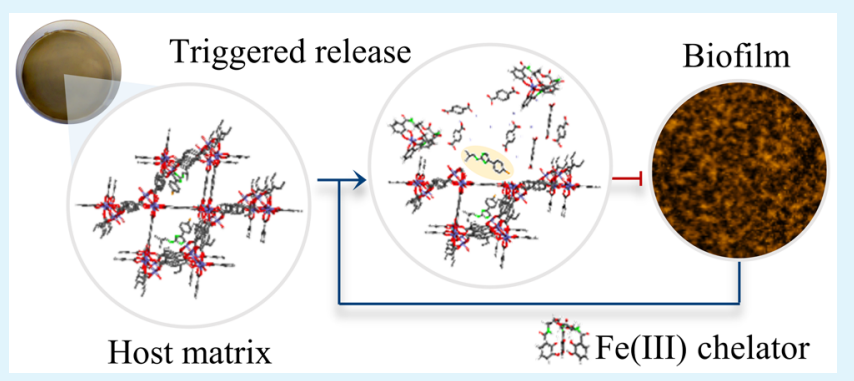
detected. The stability of MIL-88B $(\mathrm{Fe})$ in distilled water and tryptic soy broth medium is investigated, together with the ability of iron(III) chelators to serve as a trigger for controlled decomposition of MIL- $88 \mathrm{~B}(\mathrm{Fe})$ by metal complexation. Organic iron chelators are used to mimic the iron chelating function of siderophores, which are specific molecules excreted by biofilm-forming bacteria. Trisodium citrate is able to chelate metal ions from the junctions of the framework. By sequestration of these metal ions, the host matrix is partially degraded, resulting in an antibiofilm compound release. Finally, the antibiofilm properties against Salmonella Typhimurium are validated by monitoring biofilm growth on MOF layers either loaded or not with aminoimidazole. A strong proof-of-concept is shown for efficient inhibition of biofilm growth through triggered antibiofilm compound release.

KEYWORDS: metal-organic framework, biofilm, stimulus responsive, iron, Salmonella, active molecule release

\section{INTRODUCTION}

Metal-organic frameworks (MOFs) are a recent class of highly porous crystalline materials consisting of metal ions and organic ligands connected through coordination bonds. ${ }^{1-8}$ Initial applications of MOFs include gas storage, ${ }^{9,10}$ separation, $^{11}$ and catalysis. ${ }^{12}$ Because of their high and regular porosity and the possibility to tune structure and composition, more recent application fields of MOFs are in biomedicine, drug encapsulation and delivery, imaging and chemical sensing. ${ }^{13-15}$ MOFs can function as appropriate matrices to deliver active molecules in a controlled way. Whereas alternative materials often suffer from poor drug loadings, high drug loadings are possible in MOFs, due to their high porous volume. ${ }^{16}$ Specifically, biodegradable iron(III) polycarboxylate MOFs have been proposed for controlled delivery of therapeutic agents under physiological conditions simulating those of the human body. ${ }^{17}$ Furthermore, MIL-88B(Fe) is like MIL-53(Fe) (MIL stands for Materials from Institut Lavoisier), a breathing material. This can have an additional advantage: after adsorption of the guest molecules, the framework can be closed around the adsorbed compounds to prevent a spontaneous release in water. ${ }^{7} \mathrm{MIL}-88 \mathrm{~B}(\mathrm{Fe})$ is built from trimers of oxocentered iron(III) octahedra and terephthalic acid as a linker (Figure 1C,D). Controlled release is desired, and notably, stimuli-responsive MOFs have recently been described. For example, cations can be used as an external stimulus to trigger procainamide release from bio-MOF-1. ${ }^{18}$

In most aqueous environments, bacteria switch between a free-living state and a biofilm mode of growth. ${ }^{19}$ Most bacteria adhere to surfaces and form biofilms; for example, Salmonella adheres to abiotic and biotic surfaces such as glass, plastics, stainless steel, and epithelial cells. ${ }^{20}$ Biofilms are defined as structured communities of bacterial cells enclosed in a gel-like matrix of extracellular polymeric substances, in which they are protected against numerous stress factors. ${ }^{21}$ As such, bacteria in biofilms are more resistant toward host immune systems, disinfectants, and antibiotics. ${ }^{22,23}$ Besides causing infections associated with surgical implants, biofilms increase steel corrosion and biofouling, contaminate food preparation, and reduce heat transfer. ${ }^{23-25}$ Surfaces in slaughterhouses, food and

Received: November 4, 2016

Accepted: January 12, 2017

Published: January 12, 2017 

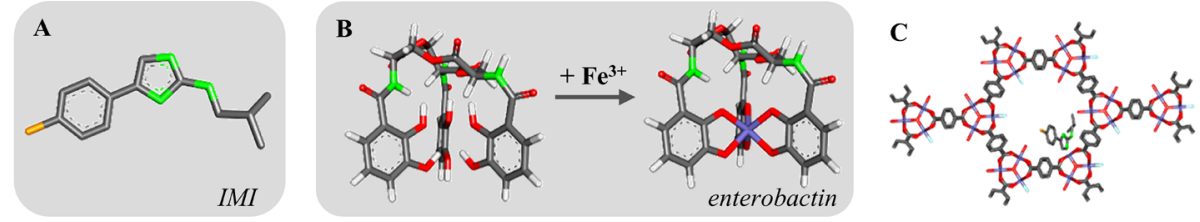

D Triggered release of IMI from MIL-88B(Fe)
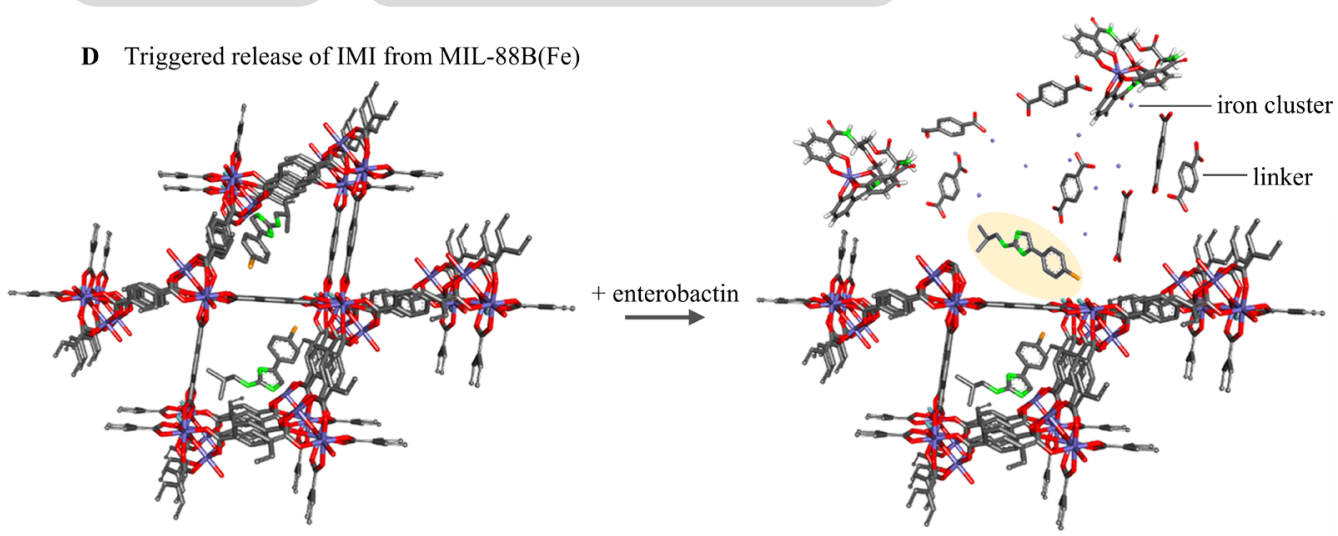

Figure 1. Concept illustration of embedded antibiofilm compound release from MIL- $88 \mathrm{~B}(\mathrm{Fe})$ by competitive metal complexation. Depicted are (A) the chemical structure of the antibiofilm compound 5-(4-chlorophenyl)- $\mathrm{N}$-(2-isobutyl)-2-aminoimidazole (IMI), (B) chelation of Fe(III) by the siderophore enterobactin, (C) adsorption of IMI in MIL- $88 \mathrm{~B}(\mathrm{Fe})$ visualized from the c-axes, and (D) the triggered release of IMI from MIL$88 \mathrm{~B}(\mathrm{Fe})$. Hydrogen atoms are hid except for the enterobactin molecules in $(\mathrm{B})$ and $(\mathrm{D}) .(\mathrm{C}=$ dark gray; $\mathrm{O}=$ red; $N=$ green; $\mathrm{Fe}=$ purple; $\mathrm{H}=$ light gray; $\mathrm{Cl}=$ orange).

feed industry, stables, and animal drinking-water systems are some examples where one may apply antibiofilm coatings to prevent Salmonella biofilm growth. In these types of applications, the primary pathogen is Salmonella, and the focus is on preventing attachment of bacteria and initial biofilm formation of bacteria to keep them as free-living organisms so they can be easily removed by liquid flow or by cleaning agents and disinfectants in case of applications in, respectively, pipelines and food processing equipment.

In order to prevent biofilm formation, different concepts and combinations have been explored. ${ }^{26}$ First, antiadhesive polymer coatings such as poly(ethylene glycol) and intrinsically bioactive materials with antibacterial properties like silverbased materials and chitosan derivatives can reduce biofilm formation. ${ }^{27,28}$ Furthermore, bioactive antibacterial coatings, for example, chlorhexidine grafted on titanium ${ }^{29}$ and also biomaterials delivering antimicrobial peptides ${ }^{25,30}$ (e.g., nisin $^{26,31,32}$ ) exist. Moreover, several antimicrobial Ag-, $\mathrm{Cu}-$, or Co-based MOFs based on simple, cheap, and easily accessible commercial ligands have been explored, but in all these cases, toxic metal ions are released into the environment. $^{33-35}$

A novel concept is to induce the release from MOFs of small molecules able to prevent biofilm formation. Recently, several series of preventive antibiofilm compounds based on the 5-aryl2-aminoimidazole scaffold have been developed, which specifically target biofilm formation without affecting free-living growth. ${ }^{23,36-38}$ Imidazoles inhibit matrix production in Salmonella by inhibiting the transcription of $\mathrm{CsgD}$, which is the master regulator of matrix production. ${ }^{39}$ Since matrix is a public good, resistant cells are expected to share the advantage with sensitive cells without sharing the cost. In such cases, selection against resistance is expected because sensitive cells will thrive well and overgrow the resistant cells. ${ }^{40}$ Therefore, resistance against these compounds is expected to emerge much more slowly than against classical microbiocidal compounds. 5-(4-Chlorophenyl)- $\mathrm{N}$-(2-isobutyl)-2-aminoimida- zole (IMI) (Figure 1A) is one of the most potent and least cytotoxic representatives. ${ }^{41}$ Stimulated release will decrease the appearance of antimicrobial agents in the environment, effecting an even further decrease in selective pressure toward resistance. Moreover, by triggering the release, the coatings' lifetime can be prolonged. To lower the release of antimicrobial agents in the environment, a specific trigger is needed to initiate active molecule release only when biofilm formation is threatening. Siderophores, a specific type of molecule excreted by biofilms, are an interesting candidate trigger. ${ }^{42}$ Siderophores are capable of chelating iron, among other metal ions; they enable bacteria to attach to surfaces and make iron(III) available to their internal iron metabolism. Because of the high affinity of siderophores for iron(III), an iron-based MOF was chosen. Because iron is an essential element for almost all bacteria and iron(III) is poorly available in aerobic environments at neutral $\mathrm{pH}$, bacterial siderophores are very widespread. Three examples of these siderophores excreted by Salmonella enterica subsp. enterica serovar Typhimurium, later on named $S$. Typhimurium, are the catecholates enterobactin and salmochelin and a carboxylate type of siderophore, citrate. The acquisition of iron(III) by siderophores from a Fe-bearing montmorillonite clay has already been described. ${ }^{43}$

In this study, we develop a proof-of-concept for smart, stimulus-responsive MOF coatings as a host matrix for the release of embedded antibiofilm compounds by competitive metal complexation (Figure 1). The aims are to use biocompatible linkers and metal ions to form a well-adherent MOF layer, to exert precise control over the release of the biofilm inhibitor, and to understand how the antibiofilm compound interacts with the MOF lattice and how eventually it is released. Therefore, two materials are chosen, MIL- $88 \mathrm{~B}(\mathrm{Fe})$ with chemical formula $\mathrm{Fe}^{\mathrm{III}}{ }_{3} \mathrm{O}(\mathrm{OH})\left(\mathrm{H}_{2} \mathrm{O}\right)_{2}\left\{\mathrm{O}_{2} \mathrm{C}-\mathrm{C}_{6} \mathrm{H}_{4}-\right.$ $\left.\mathrm{CO}_{2}\right\}_{3} \cdot n \mathrm{H}_{2} \mathrm{O}$ and a hydrophobic variant of this material with $3.6 \pm 0.2 \mathrm{wt} \%$ of palmitic acid as a lattice terminating group $\left(\mathrm{Fe}^{\mathrm{III}}{ }_{3} \mathrm{O}(\mathrm{OH})\left(\mathrm{H}_{2} \mathrm{O}\right)_{2}\left\{\mathrm{O}_{2} \mathrm{C}-\mathrm{C}_{6} \mathrm{H}_{4}-\mathrm{CO}_{2}\right\}_{3}\left[\mathrm{CH}_{3}\right.\right.$ $\left.\left.\left(\mathrm{CH}_{2}\right)_{14} \mathrm{COOH}\right]_{0.1} \cdot n \mathrm{H}_{2} \mathrm{O}\right) .{ }^{44,45}$ In Figure 1 , respectively, the 
antibiofilm compound IMI, the chelation of $\mathrm{Fe}(\mathrm{III})$ by the siderophore enterobactin, and the adsorption of IMI on MIL$88 \mathrm{~B}(\mathrm{Fe})$ are depicted together with the concept illustration and the structure of MIL- $88 \mathrm{~B}(\mathrm{Fe})$.

\section{MATERIALS AND METHODS}

MOF-Synthesis. The solvothermal synthesis of MIL- $88 \mathrm{~B}(\mathrm{Fe})$ was carried out according to a slightly modified literature synthesis. ${ }^{44}$ In a $250 \mathrm{~mL}$ Schott bottle, $2.7 \mathrm{~g}$ iron(III) chloride hexahydrate $(10 \mathrm{mmol}$, Merck, ACS Reag.), and $1.66 \mathrm{~g}$ terephthalic acid $(10 \mathrm{mmol}$, Aldrich,

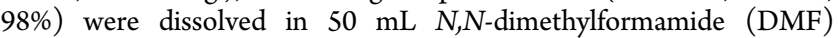
(Acros organics, extra pure). Sodium hydroxide $(0.32 \mathrm{~g}, 8 \mathrm{mmol}$, Fisher, analytical reagent grade) was dissolved in $4 \mathrm{~mL}$ of distilled water and added to the mixture. The reaction mixture was sealed and kept for $18 \mathrm{~h}$ in a preheated oven at $353 \mathrm{~K}$. The resulting orange powder was filtered and washed with DMF and ethanol (Fisher, absolute). Afterward, the material was dried overnight at $333 \mathrm{~K}$. Additionally, a hydrophobic variant of MIL- $88 \mathrm{~B}(\mathrm{Fe})$ was synthesized, namely, MIL- $88 \mathrm{~B}(\mathrm{Fe}) \mathrm{PA}$, with palmitic acid as an externally adsorbed hydrophobic compound. For the synthesis of MIL-88B(Fe)PA, $12.7 \mathrm{~g}$ of palmitic acid ( $50 \mathrm{mmol}$, TCI) was added to the solution containing the linker and metal ion, followed by the same solvothermal procedure. $^{45}$

Batch Adsorption of Antibiofilm Compound. Liquid-phase batch experiments were performed at $298 \mathrm{~K}$ in $1.8 \mathrm{~mL}$ glass vials containing $25 \mathrm{mg}$ of adsorbent and $1.8 \mathrm{~mL}$ of an ethanol solution of IMI. Different concentrations of the antibiofilm compound were contacted with the adsorbents, MIL- $88 \mathrm{~B}(\mathrm{Fe})$ and MIL-88B(Fe)PA. Uptakes were directly calculated from gas chromatography output data. In a standard procedure, the materials were pretreated at $333 \mathrm{~K}$ in an oven overnight under atmospheric conditions. Adsorption isotherms were constructed by plotting the uptake, in IMI per $\mathrm{g}$ of MOF (mmol/g) and wt \% IMI, versus the residual equilibrium concentration in solution $(\mathrm{M})$.

MOF Coating Procedure. MOF coatings were formed by deposition on small polystyrene Petri dishes $(60 \mathrm{~mm} \varnothing)$ by solvent evaporation. The adsorbent, e.g. MIL-88B(Fe) or MIL-88B(Fe)PA, possibly loaded with antibiofilm compound, was suspended in heptane $(5 \mathrm{mg} / \mathrm{mL})(99+\%$, Fisher) and sonicated for $10 \mathrm{~min}$. Then $1 \mathrm{~mL}$ of suspension was deposited on the Petri dish by evaporation of the solvent; this step was repeated four times to obtain a homogeneous MOF coating.

Material Characterization. The host matrix was characterized with powder X-ray diffraction (PXRD) patterns and scanning electron microscopy (SEM). For measurements after immersion in an organic chelator-containing solution, $\mathrm{Na}_{3}$ citrate and catechol are used. PXRD measurements of MIL- $88 \mathrm{~B}(\mathrm{Fe})$ and MIL- $88 \mathrm{~B}(\mathrm{Fe}) \mathrm{PA}$ were performed using a STOE Stadi MP combi diffractometer with a $\mathrm{Cu} \mathrm{K} \alpha$ radiation as X-ray source. SEM was measured with a FEI/Philips XL30 FEG microscope. An UV-vis-NIR Lambda 950 PerkinElmer spectrophotometer equipped with a $150 \mathrm{~mm}$ diameter integrating sphere (coated with Spectralon) was used to record DRS spectra. The samples were placed in a $1 \mathrm{~mm}$ quartz cuvette in a Teflon sample holder and covered with a quartz plate for measurements. The reflection spectra were measured against $\mathrm{BaSO}_{4}$ as a highly reflective standard.

Framework Degradation and IMI Release. For the MOF degradation study and IMI release monitoring, coatings of $25 \mathrm{mg}$ of both MOFs on a $28 \mathrm{~cm}^{2}$ polystyrene Petri dish were submerged by 10 $\mathrm{mL}$ of medium (distilled water or $1 / 20$ tryptic soy broth (TSB) medium) and kept at $298 \mathrm{~K}$ for $24 \mathrm{~h}$. The spontaneous degradation and release were compared to the triggered degradation and release in the presence of the external chelator $\mathrm{Na}_{3}$ citrate. $\mathrm{Na}_{3}$ citrate concentrations were varied between 0 and $10 \mathrm{mM}$. The released amount of IMI was measured with UV-vis spectroscopy on a PerkinElmer Lambda $12 \mathrm{UV}$-vis spectrophotometer at $268 \mathrm{~nm}$. As a reference, a similar MOF coating in distilled water or $1 / 20 \mathrm{TSB}$ without adsorbed IMI was used. The degradation and hence the relative stability of the MOFs in distilled water and 1/20 TSB medium, were calculated based on the released iron concentration in the media.
The concentration of metal ions in the immersion liquid was measured by inductively coupled plasma atomic emission spectroscopy (ICPAES), on an Ultima apparatus from the Jobin Yvon Emission Horiba Group. For successive measurements, again $10 \mathrm{~mL}$ of the same medium is added to the remaining coating and the procedure is repeated.

Biofilm Growth Assay. Biofilms of $S$. Typhimurium strain ATCC14028 (fluorescently labeled by DsRed, encoded on plasmid pFPV25.1) were grown on the bottom of small $(60 \mathrm{~mm} \varnothing)$ polystyrene Petri dishes covered with MOF coating and filled with $10 \mathrm{~mL}$ of $1 / 20 \mathrm{TSB}$. TSB medium is a nutritious medium used as a culture broth to grow aerobic bacteria. Diluted TSB is more effective in promoting biofilm production by Salmonella spp. ${ }^{46}$ An overnight culture of ATCC14028 grown in LB broth was diluted 1/200 in the Petri dishes after which they were incubated under static conditions at $298 \mathrm{~K}$ for $24 \mathrm{~h}$. The biofilm layer on the bottom of the plates was scraped off (and passed multiple times to a needle), and the number of biofilm colony forming units (CFUs) was determined. This method was used to determine biofilm formation on MIL-88B(Fe) and MIL$88 \mathrm{~B}(\mathrm{Fe}) \mathrm{PA}$ containing both adsorbed IMI. MIL- $88 \mathrm{~B}(\mathrm{Fe})$ and MIL$88 \mathrm{~B}(\mathrm{Fe}) \mathrm{PA}$ without active compound and an empty Petri dish were used, respectively, as reference and control.

\section{RESULTS AND DISCUSSION}

Stability and Degradation of the Host Matrix. An important property of an appropriate host matrix is its stability in aqueous conditions or bacterial growth media. Besides being stable, the host matrix needs to be susceptible toward partial triggered degradation by externally added chelators or siderophores. In order to assess the stability of both MIL- $88 \mathrm{~B}(\mathrm{Fe})$ and MIL- $88 \mathrm{~B}(\mathrm{Fe}) \mathrm{PA}$ in distilled water and TSB medium, the PXRD diffractograms of the two materials are analyzed. The diffraction patterns in Figure 2 show that there are no changes to the structure when palmitic acid is added to the synthesis of MIL- $88 \mathrm{~B}(\mathrm{Fe})$ to form MIL- $88 \mathrm{~B}(\mathrm{Fe}) \mathrm{PA}$, which is confirmed by the elemental composition in Table $\mathrm{S} 1{ }^{45}$ Hence the crystal structure of both materials is the same; palmitate functions as a lattice terminating hydrophobic monolayer around MIL$88 \mathrm{~B}(\mathrm{Fe}) \mathrm{PA}$. After incubation of both materials for $24 \mathrm{~h}$ in distilled water and TSB medium (1/20 diluted), no peak changes are discernible (Figure $2 \mathrm{a}-\mathrm{c}$ ). It follows that both MIL- $88 \mathrm{~B}(\mathrm{Fe})$ and MIL-88B $(\mathrm{Fe}) \mathrm{PA}$ are stable in distilled water and TSB. To simulate the degradation of the host matrix by siderophores, catechol, as the chelating moiety of enterobactin and another natural chelator, $\mathrm{Na}_{3}$ citrate, were used. For both materials, PXRD diffraction patterns were recorded after $24 \mathrm{~h}$ of immersion into chelator-containing solutions. After contact with $0.1 \mathrm{mM}$ catechol (chelator to iron molar ratio 1/100) or $0.2 \mathrm{mM}$ citrate (chelator to iron molar ratio of 1 to 50 ), the diffractograms are still identical to the corresponding patterns after synthesis; hence the crystallinity of the MOFs is retained although part of the MOF is degraded according to the ICPAES results discussed further on.

To determine whether these MOFs are partially degraded by added chelators, SEM micrographs were recorded (Figure 3). First, the morphology of the crystals of MIL- $88 \mathrm{~B}(\mathrm{Fe})$ (Figure $3 \mathrm{~A}$ ) is compared to that of MIL-88B(Fe)PA (Figure $3 \mathrm{~B}-\mathrm{D}$ ). Deposition of MIL-88B(Fe) and MIL-88B(Fe)PA by solvent evaporation on a Petri dish is a simple method to obtain MOF coatings. The interactions between $\mathrm{MIL}-88 \mathrm{~B}(\mathrm{Fe})$ and a hydrophobic surface such as polystyrene, are not strong enough to prevent the detachment of the MIL- $88 \mathrm{~B}(\mathrm{Fe})$ crystals from the surface when a strong liquid flow is exerted, although by gently adding $10 \mathrm{~mL}$ water, the coating stability is maintained. MIL-88B(Fe)PA, a hydrophobic variant of MIL-88B(Fe), was 

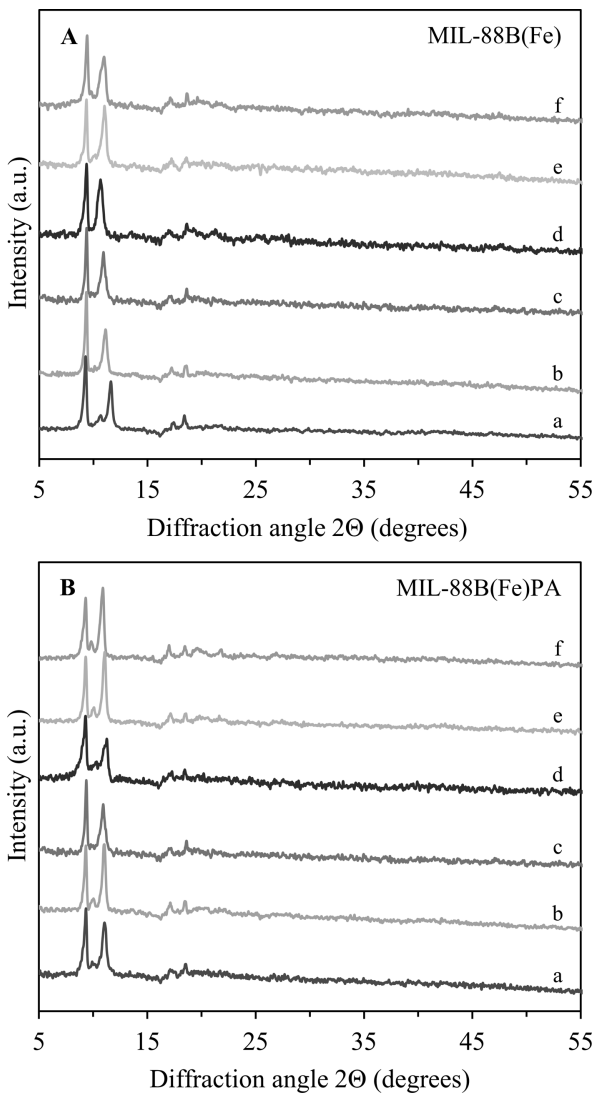

Figure 2. PXRD diffraction patterns of (A) MIL-88B(Fe) and (B) MIL-88B(Fe)PA, in different conditions compared to (a) the assynthesized MOF. The PXRD patterns of MIL- $88 \mathrm{~B}(\mathrm{Fe})$ and MIL$88 \mathrm{~B}(\mathrm{Fe}) \mathrm{PA}$ are retained after immersion in (b) distilled water and (c) $1 / 20$ TSB medium and after contact with two chelators, namely, (d) $0.1 \mathrm{mM}$ catechol and (e) $0.2 \mathrm{mM} \mathrm{Na}_{3}$ citrate. After (f) loading MIL$88 \mathrm{~B}(\mathrm{Fe})$ or MIL- $88 \mathrm{~B}(\mathrm{Fe}) \mathrm{PA}$ with the antibiofilm compound IMI, the crystal structure of both MOFs is retained.

developed to further increase the adherence to the polystyrene Petri dishes. A MIL-88B(Fe)PA coating on a Petri dish is shown in Figure 3B. Overall, the shape of the MIL- $88 \mathrm{~B}(\mathrm{Fe})$ and MIL- $88 \mathrm{~B}(\mathrm{Fe}) \mathrm{PA}$ crystals is the same; only the length of MIL-88B(Fe)PA crystals is shortened because of slower crystal growth along the $c$-axis in the presence of the synthesis modulating agent, palmitic acid. ${ }^{45}$ Using MIL-88B(Fe)PA, a $90 \%$ surface coverage of the Petri dish was reached, and a rather rough surface is obtained (Figure $3 \mathrm{~B}$ ). SEM micrographs of
MIL-88B(Fe)PA in Figure 3D show clear defect formation after immersion in a chelator-containing solution of $10 \mathrm{mM} \mathrm{Na}_{3}$ citrate although the residual material is still crystalline as proven by the PXRD patterns (Figure 2). Small cracks are visible and the apex of the crystals seems to be more sensitive to degradation by chelation. This suggests that the edge sites corresponding to the crystallographic $\langle 11 \overline{2} 0\rangle$ set of directions are susceptible to be attacked first by a chelator, while most well-formed crystallites do not suffer any perceptible degradation.

The fraction of MIL-88B $(\mathrm{Fe})$ and MIL-88B $(\mathrm{Fe}) \mathrm{PA}$ degraded by $\mathrm{Na}_{3}$ citrate as a chelator was determined by measuring the iron(III) concentration in solution with ICP-AES. The spontaneous degradation in water, in the absence of a chelator or siderophore, was compared to the "triggered" degradation by the external chelator $\mathrm{Na}_{3}$ citrate (Figure 4). In distilled water,

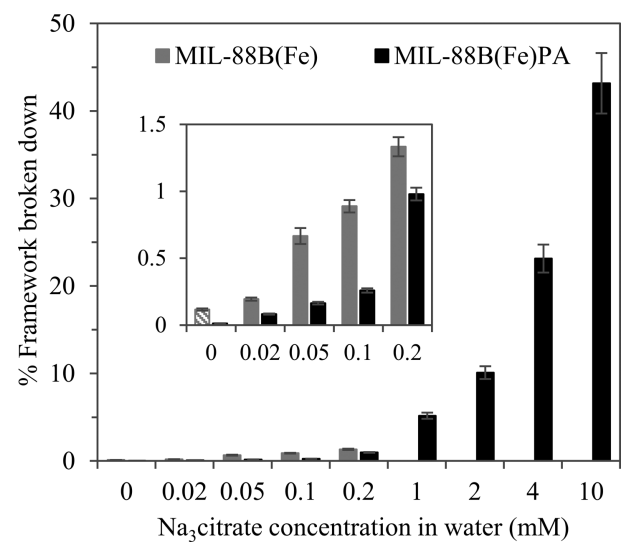

Figure 4. Degradation of MIL-88B(Fe) and MIL-88B(Fe)PA plotted against chelator concentration in water $(\mathrm{mM})$. The percentage of the framework that is broken down is calculated from the concentration of the metal ion $\left(\mathrm{Fe}^{3+}\right)$ released from the host matrix. Without the addition of external chelator, the degradation is called spontaneous (shaded).

the concentration of iron spontaneously released into solution is lower than $0.01 \mathrm{mM}$. The concentration of enterobactin siderophores in bacterial cultures varies from 2 to $20 \mu \mathrm{M}$, which is comparable with the salmochelin production in bacterial media. ${ }^{47}$ As the affinity of externally added organic chelators for $\mathrm{Fe}(\mathrm{III})$ is lower than that of enterobactin $\left(\mathrm{K} \approx 10^{49} \mathrm{~L} \mathrm{~mol}^{-1}\right)$, higher concentrations of external chelator were added. ${ }^{42}$
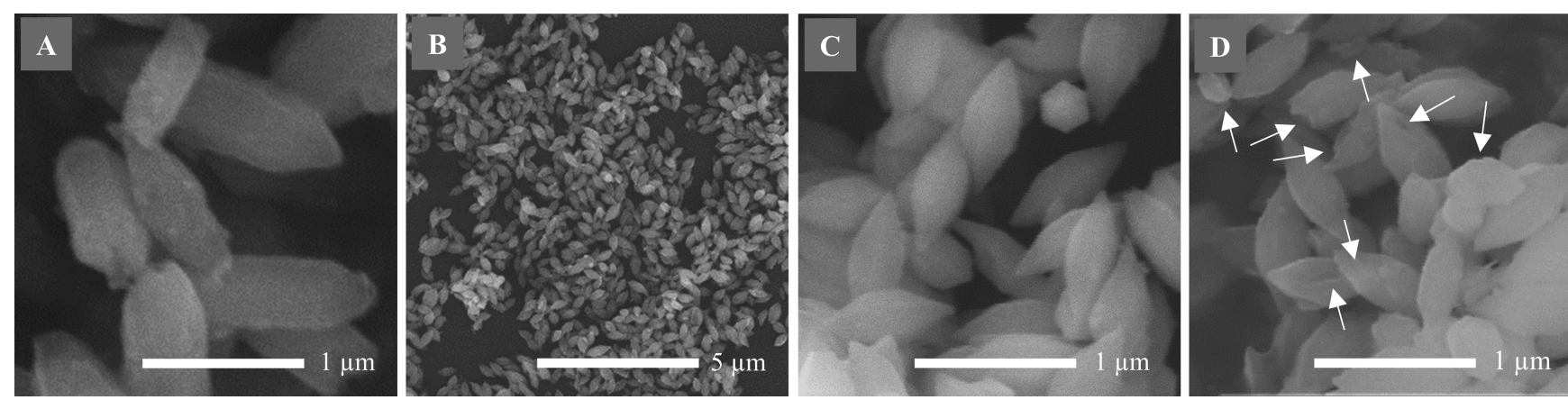

Figure 3. SEM pictures of (A) MIL-88B(Fe), (B) a MIL-88B(Fe)PA coating on a small Petri dish; MIL-88B(Fe)PA after contact with (C) water and with (D) $10 \mathrm{mM} \mathrm{Na}_{3}$ citrate. The degradation of the MOF crystals by an external chelator is indicated by arrows. Overall crystal size of MIL$88 \mathrm{~B}(\mathrm{Fe}) \mathrm{PA}$ is smaller than for MIL-88B $(\mathrm{Fe})$. 
When both host matrices are immersed in increasing concentrations of $\mathrm{Na}_{3}$ citrate, the degradation by disruption of the metal-ligand junctions is gradually enhanced (Figure 4). Thus, compared to the spontaneous degradation of the host matrix, the triggered degradation is considerably higher. From 0 to $0.2 \mathrm{mM}$ chelator, more of the material is degraded in case of MIL-88B(Fe) than for MIL-88B(Fe)PA. Degradation at higher $\mathrm{Na}_{3}$ citrate concentrations is also shown for MIL-88B(Fe)PA. The overall tendency is to degrade the material roughly in a 1:2 molar ratio between $\mathrm{Fe}^{3+}$ and citrate. If $1 \mathrm{mM}$ of $\mathrm{Na}_{3}$ citrate is added to a MIL- $88 \mathrm{~B}(\mathrm{Fe}) \mathrm{PA}$ coating, approximately $5 \%$ or 0.54 $\mathrm{mM} F$ is measured in $10 \mathrm{~mL}$ solution, corresponding to half of the molar chelator amount in solution. At concentrations below $0.2 \mathrm{mM}$, the percentage of framework broken down deviates to lower values; so it seems that a threshold concentration of chelator is needed to achieve significant breakdown of the materials.

To control the repeatability of the degradation, a $0.2 \mathrm{mM}$ $\mathrm{Na}_{3}$ citrate solution was added five times to the same host matrix (Figure 5). For successive measurements, again $10 \mathrm{~mL}$

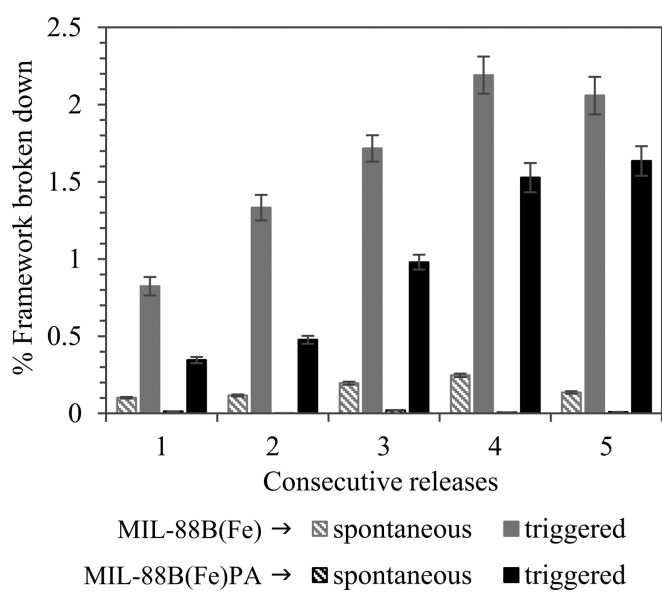

Figure 5. Degradation of MIL- $88 \mathrm{~B}(\mathrm{Fe})$ and MIL- $88 \mathrm{~B}(\mathrm{Fe}) \mathrm{PA}$ by 0.2 $\mathrm{mM} \mathrm{Na} \mathrm{Na}_{3}$ citrate as an external chelator. The percentage of the framework broken down based on the $\mathrm{Fe}^{3+}$ concentration released by degradation of the host matrix is measured five times in a row. The spontaneous release (shaded) is smaller than the triggered degradation when an external chelator is added to the water in contact with the host matrix. Values for framework breakdown are noncumulative.

of the citrate solution was added to the remaining material. With consecutive releases, the difference between spontaneous and triggered degradation is confirmed. During the five consecutive exposures to water, the amount of MOF degraded spontaneously is very low. In comparison, in the triggered degradation of the host matrix, a higher iron(III) concentration in solution is measured even after four times. At first, the less strongly bound metal-linker junctions are degraded, probably around edges of the material. After the fifth release, the triggered degradation, induced by $0.2 \mathrm{mM}$ of $\mathrm{Na}_{3}$ citrate, still reaches $0.4 \mathrm{mM}$ of $\mathrm{Fe}^{3+}$ released into the solution compared to $0.02 \mathrm{mM}$ spontaneously (Figure 5). The possibility of consecutive releases shows that the material may be reused.

In summary, the host matrix is indeed stable in aqueous conditions but partially degradable by competitive chelation by, for example, $\mathrm{Na}_{3}$ citrate. The presence of an external chelator could thus induce local disassembly of the MIL- $88 \mathrm{~B}(\mathrm{Fe})$ and MIL-88B(Fe)PA MOFs.
Encapsulation of Antibiofilm Compounds. As MIL$88 \mathrm{~B}(\mathrm{Fe})$ is a flexible, breathing material, ethanol was used as solvent to open up the pores of the framework. According to the PXRD patterns of MIL- $88 \mathrm{~B}(\mathrm{Fe})$ and MIL-88B(Fe)PA, the crystal structure of both materials is retained after adsorption of IMI (Figure 2f). In Figure 6, the single compound adsorption

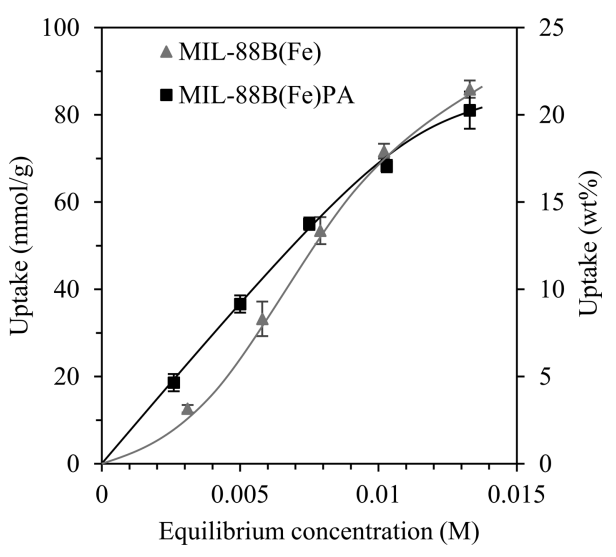

Figure 6. Adsorption isotherm for single-compound adsorption of IMI from ethanol on MIL-88B $(\mathrm{Fe})$ (gray $\boldsymbol{\Delta}$ ) and MIL-88B(Fe)PA ( $(\boldsymbol{\square})$ at $298 \mathrm{~K}$.

isotherms of IMI from ethanol on MIL- $88 \mathrm{~B}(\mathrm{Fe})$ and MIL$88 \mathrm{~B}(\mathrm{Fe}) \mathrm{PA}$ at $298 \mathrm{~K}$ are presented. It is favorable that after adsorption of 10 wt \% IMI on MIL- $88 \mathrm{~B}(\mathrm{Fe})$, the material is sufficiently hydrophobic to adhere well to a polystyrene Petri dish. When MIL- $88 \mathrm{~B}(\mathrm{Fe})$ or MIL- $88 \mathrm{~B}(\mathrm{Fe}) \mathrm{PA}$ are used as a host matrix, up to $20 \mathrm{wt} \%$ of IMI can be adsorbed. Because of the low offered concentrations of IMI, the saturation uptake is not reached. Clearly, from a fully loaded material, loosely bound IMI would be readily released; therefore, it was preferred to limit the occupancy of the pores with IMI to a partial loading of $10 \mathrm{wt} \%$.

The initial affinity of a host matrix for a certain compound is reflected in the slope of the adsorption isotherm at low concentrations. Although at higher concentrations no difference is observed between MIL- $88 \mathrm{~B}(\mathrm{Fe})$ and MIL- $88 \mathrm{~B}(\mathrm{Fe}) \mathrm{PA}$, the affinity of MIL- $88 \mathrm{~B}(\mathrm{Fe}) \mathrm{PA}$ for IMI is at the lowest concentrations clearly higher than that of MIL-88B(Fe). IMI will be attracted more easily toward the hydrophobic framework because of hydrophobic interactions between the antibiofilm compound and palmitate groups on the surface. As shown in Figure 7, the overall degradation of the MOF itself is not influenced by the weight percentage of IMI adsorbed on the Fe-MOF. In Figure 7A, the concentration of $\mathrm{Na}_{3}$ citrate in water is plotted against the framework degradation for MIL$88 \mathrm{~B}(\mathrm{Fe}) \mathrm{PA}$ either nonloaded or loaded with 5 or $10 \mathrm{wt} \% \mathrm{IMI}$. For the spontaneous as well as the triggered release, no difference in the degradation of the framework is observed.

For the release, too high losses due to spontaneous release should be avoided. Therefore, the flexibility of the host matrix in different solvents is exerted. By using a flexible MOF and a solvent that opens up the pores at the adsorption stage, the matrix can be closed subsequently around the embedded molecules to prevent a high spontaneous release in water. The difference in the PXRD diffraction patterns between MIL$88 \mathrm{~B}(\mathrm{Fe})$ wetted in water and ethanol is shown in Figure $7 \mathrm{~B}$ together with the simulated pattern of the open MIL- $88 \mathrm{~B}(\mathrm{Fe})$ (based on the CIF file from CCDC). ${ }^{48}$ The flexible structure of 

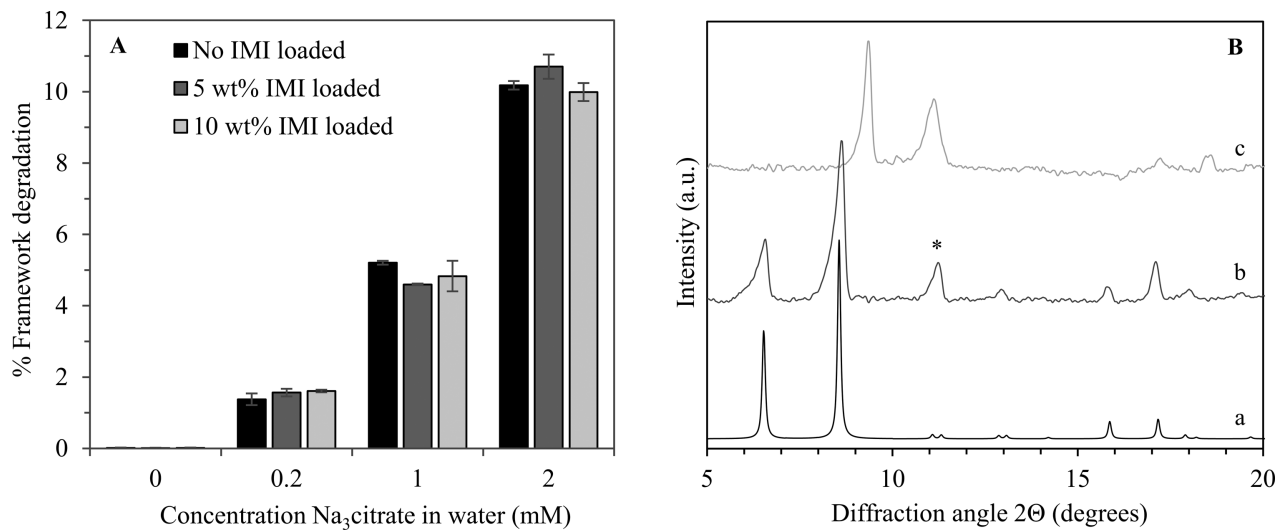

Figure 7. Degradation of MIL-88B(Fe)PA plotted against chelator concentration in water $(\mathrm{mM})$ for different loadings of IMI on the host matrix. (A) The spontaneous degradation is shown in shaded bars. (B) The reference PXRD diffraction pattern of MIL-88B(Fe) in (a) open form and wetted in (b) ethanol or (c) water. When exposed to ethanol, the material primarily shows an open conformation, as well as a minor fraction of the closed conformation of MIL- $88 \mathrm{~B}(\mathrm{Fe})$ (marked with asterisk).

MIL-88B $(\mathrm{Fe})$ can be opened in ethanol; indeed the reflections move to lower diffractions angles, which corresponds to larger distances between the crystallographic planes. This provides evidence that the material is opened in ethanol, which probably facilitates the uptake of the IMI; in contrast, the material reverts to its closed, narrow pore form when it is submerged in water for release.

IMI is successfully embedded in both MOFs because of the interactions between the antibiofilm compound and the framework. Considering the chemical formula $\mathrm{Fe}^{\mathrm{III}}{ }_{3} \mathrm{O}(\mathrm{OH})$ $\left(\mathrm{H}_{2} \mathrm{O}\right)_{2}\left\{\mathrm{O}_{2} \mathrm{C}-\mathrm{C}_{4} \mathrm{H}_{4}-\mathrm{CO}_{2}\right\}_{3} \cdot n \mathrm{H}_{2} \mathrm{O}$, removal of two water molecules generates two coordinatively unsaturated sites (CUS) per $\mathrm{M}_{3} \mathrm{O}$ cluster in both $\mathrm{MIL}-88 \mathrm{~B}(\mathrm{Fe})$ and $\mathrm{MIL}$ $88 \mathrm{~B}(\mathrm{Fe}) \mathrm{PA}$. The nitrogen atoms of IMI may interact with the free ligation sites on the $\mathrm{Fe}^{3+}$ ions. As ferric iron has a Lewis acid character, a strong interaction with Lewis bases like 2aminoimidazoles is likely. For a loading of $10 \mathrm{wt} \%$ IMI, only 0.28 molecules of IMI are present per $\mathrm{Fe}_{3} \mathrm{O}$ cluster, implying that only $14 \%$ of the potential coordination sites are occupied. Second, IMI could also interact via its imidazole or phenyl ring with the aromatic linkers of the host matrix itself.

Upon contact between activated MIL- $88 \mathrm{~B}(\mathrm{Fe})$ or MIL$88 \mathrm{~B}(\mathrm{Fe}) \mathrm{PA}$ and IMI, the MOF changes its color from orange to dark green. The absorbance of MIL- $88 \mathrm{~B}(\mathrm{Fe})$ after synthesis and after encapsulation of IMI is measured with DRS (Figure 8). Although loaded MIL- $88 \mathrm{~B}(\mathrm{Fe})$ shows an enhanced optical absorbance in the range between 410 and $800 \mathrm{~nm}$, IMI itself has no optical absorption in the near-UV and visible range. The change in color is indicative of the change in coordination sphere of $\mathrm{Fe}$ (III) CUS cation in the activated MIL-88B $(\mathrm{Fe})$ upon interaction with IMI. As shown in Figure 8, the band at $450-460 \mathrm{~nm}$ is visible in both spectra, whereas the higher adsorption at $640 \mathrm{~nm}$ in the spectra of MIL-88B(Fe) with IMI is indicative of electronic interactions of IMI with $\mathrm{Fe}$ (III) CUS in the MOF and the formation of coordination bonds. ${ }^{49}$ The low intensity difference suggests that part of the iron sites are unaffected, which is consistent with the low adsorbed amount of IMI, while the coordination environment of part of the iron sites is changed due to the IMI adsorption.

Release of Antibiofilm Compounds. The described host matrices MIL- $88 \mathrm{~B}(\mathrm{Fe})$ and MIL-88B(Fe)PA should not only adsorb IMI but should also be able to release these active molecules. The spontaneous and triggered release of IMI from both host matrices is compared in Figure 9. The spontaneous

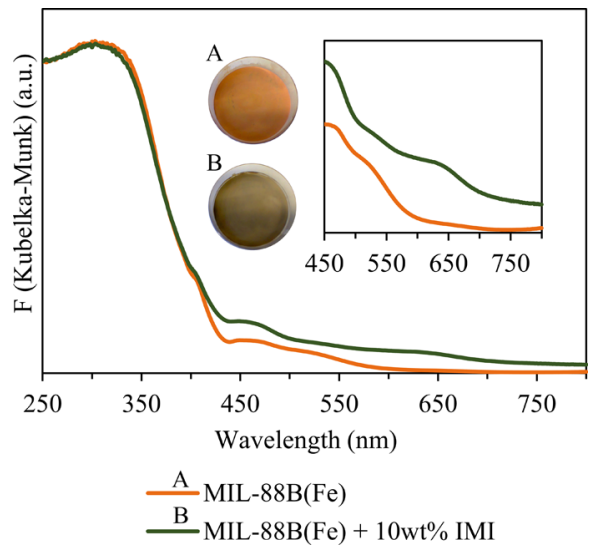

Figure 8. (Graph) Near UV-vis DRS of activated MIL-88B(Fe) and activated MIL-88B(Fe) after 10 wt \% IMI adsorption. (Pictures) MIL$88 \mathrm{~B}(\mathrm{Fe})$ coating on a Petri dish (A) unloaded and (B) loaded with IMI.

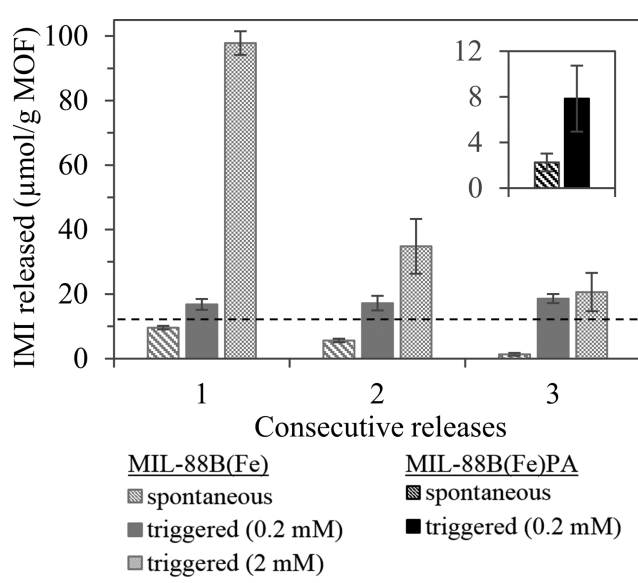

Figure 9. IMI $(\mu \mathrm{mol} / \mathrm{g}$ MOF) released from MIL- $88 \mathrm{~B}(\mathrm{Fe})$ (gray) and MIL- $88 \mathrm{~B}(\mathrm{Fe}) \mathrm{PA}$ (black) in the presence of water and chelator. Both host matrices are loaded with $10 \mathrm{wt} \%$ IMI. The same MIL- $88 \mathrm{~B}(\mathrm{Fe})$ coating is used to repeat the release twice to obtain the consecutive release profile. The $\mathrm{BIC}_{50}$ value of IMI is indicated by a dotted line.

IMI release from MIL- $88 \mathrm{~B}(\mathrm{Fe})$ loaded with 10 wt \% IMI can also be compared to the triggered release in the presence of 0.2 $\mathrm{mM}$ and $2 \mathrm{mM} \mathrm{Na}_{3}$ citrate. The release is repeatedly measured 
with the same material and after every release, $10 \mathrm{~mL}$ of fresh stock solution is added again. In Figure 9, the molar amount of IMI released per $\mathrm{g}$ of $\mathrm{MOF}$ is presented in function of the consecutive spontaneous or triggered releases.

When contacting the $10 \mathrm{wt} \%$ loaded host matrix with distilled water or TSB medium, a small amount of loosely bound IMI molecules is spontaneously released. Immersion in a $0.2 \mathrm{mM} \mathrm{Na}_{3}$ citrate-containing solution, which corresponds to a chelator-to-metal ratio of 1 to 50, increases the amount of IMI released from the host matrix. The first spontaneous release of the antibiofilm compound from MIL- $88 \mathrm{~B}(\mathrm{Fe})$ is $9.6 \mu \mathrm{mol}$ per $\mathrm{g}$ of $\mathrm{MOF}(24 \mu \mathrm{M}$ in $10 \mathrm{~mL})$ compared to $2.3 \mu \mathrm{mol}$ per $\mathrm{g}$ of MOF $(5.8 \mu \mathrm{M}$ in $10 \mathrm{~mL})$ from MIL-88B(Fe)PA. Compared to the spontaneous release of the antibiofilm compound, the triggered release by $0.2 \mathrm{mM} \mathrm{Na} \mathrm{Na}_{3}$ citrate will release an additional 7.2 and $5.6 \mu \mathrm{mol}$ IMI per g of MOF $(18 \mu \mathrm{M}$ or 14 $\mu \mathrm{M}$ in $10 \mathrm{~mL})$ for respectively MIL- $88 \mathrm{~B}(\mathrm{Fe})$ and MIL$88 \mathrm{~B}(\mathrm{Fe}) \mathrm{PA}$. Thus, in total, $16.8 \mu \mathrm{mol}$ IMI per $\mathrm{g}$ of MOF (42 $\mu \mathrm{M}$ in $10 \mathrm{~mL}$ ) is released from MIL- $88 \mathrm{~B}(\mathrm{Fe})$. According to Figure 10, the half maximal biofilm inhibitory concentration

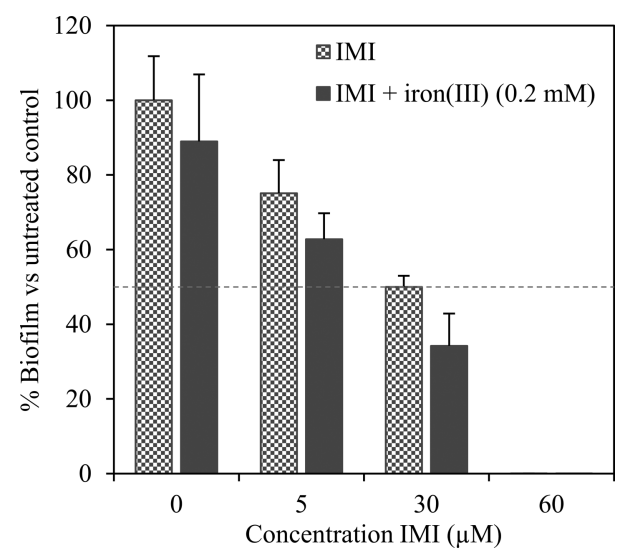

Figure 10. Biofilm inhibition of $S$. Typhimurium ATCC14028 in a Petri dish. \% Biofilm is calculated in the function of biofilm growth by an untreated control. Biofilm inhibitory activity of different IMI concentrations and in the presence and absence of $0.2 \mathrm{mM}$ iron(III) is represented. Iron(III) does not reduce the activity of IMI. The error bars indicate the positive standard deviation of three technical repeats. The dotted line indicates that biofilm growth is inhibited by half at about $30 \mu \mathrm{M}$ or $12 \mu \mathrm{mol} / \mathrm{g}$ MOF, which is the $\mathrm{BIC}_{50}$ value.

$\left(\mathrm{BIC}_{50}\right)$ of IMI is about $30 \mu \mathrm{M}$ or $12 \mu \mathrm{mol} / \mathrm{g}$ MOF. This $\mathrm{BIC}_{50}$ value indicates the concentration of the active compound that is needed to inhibit biofilm growth by half. This value is thus easily reached after triggered release from MIL- $88 \mathrm{~B}(\mathrm{Fe})$. The overall concentration $(19.8 \mu \mathrm{M}$ in $10 \mathrm{~mL})$ of IMI released from MIL- $88 \mathrm{~B}(\mathrm{Fe}) \mathrm{PA}$ does not reach the $\mathrm{BIC}_{50}$; however, local concentrations near the surface may still be high enough. If the chelator concentration is increased to $2 \mathrm{mM}$ for MIL- $88 \mathrm{~B}(\mathrm{Fe})$, the released amount of IMI is raised to $97.8 \mu \mathrm{mol}$ per $\mathrm{g}$ of MOF. By increasing the external chelator concentration, the fraction of the adsorbent that is degraded is increased, resulting in an increased release of the encapsulated active molecules. At $10 \mathrm{wt} \%$ IMI adsorbed in the host matrix, the maximum amount of IMI that can be released is $400 \mu \mathrm{mol}$ per $\mathrm{g}$ of MOF ( $1 \mathrm{mM}$ in $10 \mathrm{~mL}$ ). If between 10 and $20 \mu \mathrm{mol}$ IMI per $\mathrm{g}$ of MOF $(25 \mu \mathrm{M}$ and $50 \mu \mathrm{M})$ is measured, respectively, $2.5 \%$ to $5 \%$ of the adsorbed amount is set free after the first release.

Because stability and reusability are two important factors for using MOF coatings for the prevention of biofilm formation, three identical consecutive releases are executed. After the same host matrix with encapsulated antibiofilm compounds is three times immersed in distilled water or in a chelator-containing solution, still a sufficient amount of IMI is released. The spontaneous release is decreased after 3 times because the more loosely bound molecules have already been set free. Therefore, the difference between the spontaneous and triggered release with $0.2 \mathrm{mM}$ is increased. The triggered release with a chelator concentration of $2 \mathrm{mM}$ is reduced after three releases due to the rather large amount of the material that is already degraded. After three releases in the latter condition, about $40 \%$ of the adsorbed IMI has already been released into the medium. At that point, the most defective areas of the $\mathrm{MO}$ are already degraded, and therefore, the released amount of IMI is decreased. The relation between degradation of the Fe-MOF and the release of IMI confirms the proof-of-concept of chelator stimulated release of antibiofilm compounds.

Inhibition of Biofilm Growth. Using antibiofilm compounds, initially encapsulated in MOFs, to inhibit biofilm growth requires a well-adhering coating on, for example, a Petri dish. It is expected that the MOF coatings will strongly interact with the chelators produced by the biofilms, resulting in a partial lattice decomposition and release of biofilm inhibitors.

Initially, the possible interference of iron(III) with the activity of IMI is investigated. As shown in Figure 10, IMI is still active when used in the presence of $0.2 \mathrm{mM}$ iron(III). The combination of IMI with iron(III) even slightly enhances the antibiofilm activity.

The ability of MOF coatings to inhibit biofilm formation is tested on polystyrene coated Petri dishes. Here the dishes are filled with $1 / 20$ TSB broth inoculated with $S$. Typhimurium and incubated for $24 \mathrm{~h}$ at $298 \mathrm{~K}$. Figure 11 gives an overview of the amount of biofilm formed on uncoated dishes and dishes coated with nonloaded and loaded MOFs. All measurements are represented as percentages compared to the amount of biofilm on an uncoated Petri dish (control).

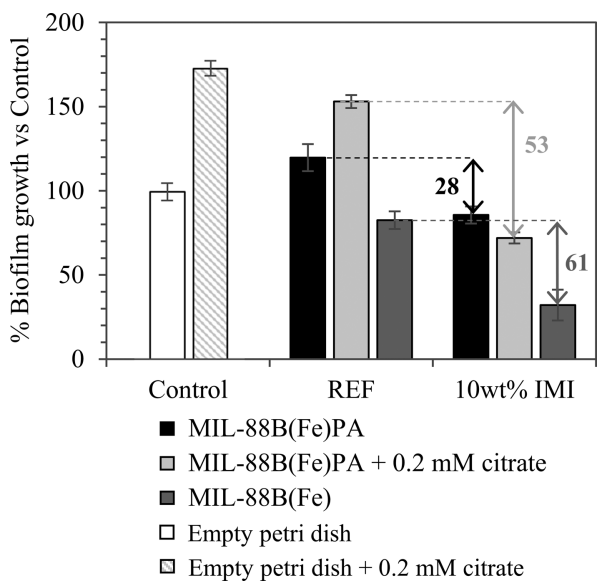

Figure 11. Biofilm inhibition of $S$. Typhimurium ATCC14028 in a Petri dish. All measurements are represented as percentages compared to the amount of biofilm on an uncoated Petri dish (Control). As reference (REF), biofilm is grown on a MIL- $88 \mathrm{~B}(\mathrm{Fe}) \mathrm{PA}$ and MIL$88 \mathrm{~B}(\mathrm{Fe}) \mathrm{MOF}$ coating without antibiofilm compound. Biofilm growth on MIL-88B $(\mathrm{Fe}) \mathrm{PA}$ and MIL-88B $(\mathrm{Fe})$ MOF coatings loaded with 10 wt \% IMI is compared to this reference. We compared the biofilm growth in the presence or absence of $0.2 \mathrm{mM}$ citrate only in the case of MIL- $88 \mathrm{~B}(\mathrm{Fe}) \mathrm{PA}$. The error bars indicate the standard deviation of three technical repeats. 
The capacity to inhibit biofilm growth is evaluated for MIL$88 \mathrm{~B}(\mathrm{Fe}) \mathrm{PA}$ and compared to that of MIL- $88 \mathrm{~B}(\mathrm{Fe})$. As shown in Figure 11, biofilm growth on a nonloaded MIL-88B(Fe)PA MOF coating is similar to biofilm growth on an uncoated control Petri dish indicating that the coating itself is nontoxic to biofilm growth. However, by loading IMI on MIL-88B(Fe)PA, the decrease in biofilm growth of $S$. Typhimurium is only minimal. To increase the amount of IMI released from the hydrophobic MIL- $88 \mathrm{~B}(\mathrm{Fe}) \mathrm{PA}$ framework and to exclude activity loss of the antibiofilm compound after adsorption or release, an external chelator, $0.2 \mathrm{mM} \mathrm{Na}_{3}$ citrate, is added to the bacterial medium. As indicated in Figure 11, the MIL$88 \mathrm{~B}(\mathrm{Fe}) \mathrm{PA}$ coating loaded with 10 wt \% IMI reduces biofilm growth in $1 / 20 \mathrm{TSB}$ medium with $0.2 \mathrm{mM} \mathrm{Na}_{3}$ citrate, by $53 \%$ compared to the reference biofilm grown on an unloaded MIL$88 \mathrm{~B}(\mathrm{Fe}) \mathrm{PA}$ coating in the presence of $0.2 \mathrm{mM} \mathrm{Na}_{3}$ citrate. This indicates that the local concentration of IMI near the surface exceeds the $\mathrm{BIC}_{50}$ value. As an increased amount of IMI can be released into the bacterial medium by the externally added chelator and biofilm growth is lowered, IMI is still active after encapsulation. Remarkably, in the absence of IMI, $\mathrm{Na}_{3}$ citrate induces biofilm formation by about $75 \%$, which is comparable for an empty Petri dish or the reference MIL-88B(Fe)PA coating after the addition of $0.2 \mathrm{mM}$ (Figure 11).

Next to MIL- $88 \mathrm{~B}(\mathrm{Fe}) \mathrm{PA}$, biofilm growth on loaded MIL$88 \mathrm{~B}(\mathrm{Fe})$ coating is evaluated compared to the reference MIL$88 \mathrm{~B}(\mathrm{Fe})$ coating in absence of any externally added chelator (Figure 11). Although for MIL-88B(Fe)PA an external chelator was needed, on MIL- $88 \mathrm{~B}(\mathrm{Fe})$ with 10 wt \% IMI, biofilm growth is inhibited by about $61 \%$ without the addition of any external chelator like citrate. This stimulus-responsive MIL$88 \mathrm{~B}(\mathrm{Fe})$ coating can thus inhibit biofilm growth even without externally added chelators. For the enhanced biofilm inhibition by a MIL- $88 \mathrm{~B}(\mathrm{Fe})$ coating compared to MIL- $88 \mathrm{~B}(\mathrm{Fe}) \mathrm{PA}$, different explanations are possible. At first, the initial affinity of MIL-88B(Fe)PA for IMI is higher. The higher the affinity, the less easily the compound can be released. Furthermore, the hydrophobic coating may not be entirely wetted by the aqueous medium. As the liquid is more on the outside of the MOF, the contact surface between the MOF and the medium is smaller and thus the release can be smaller.

For all coatings discussed so far, $25 \mathrm{mg}$ MOF loaded with 10 wt \% IMI was deposited on a $28 \mathrm{~cm}^{2}$ Petri dish. To investigate whether the inhibition of biofilm growth is dependent on the mass of the deposited MIL- $88 \mathrm{~B}(\mathrm{Fe})$ coating, different amounts of $\mathrm{MIL}-88 \mathrm{~B}(\mathrm{Fe})$ are deposited. Before deposition of the coating, the material was loaded with $10 \mathrm{wt} \%$ IMI. In Figure 12 , the biofilm growth on MIL- $88 \mathrm{~B}(\mathrm{Fe})$ coatings with different masses deposited on the Petri dish is compared to a control and reference coating. Inhibition of biofilm growth is visible for all coatings. Moreover, the inhibition increases with increasing mass of the coating and biofilm is completely inhibited if a 35 $\mathrm{mg}$ coating is deposited in a small Petri dish. The higher the surface coverage and the more material present that is potentially degradable, the higher the inhibition of biofilm growth.

\section{CONCLUSIONS}

In summary, MIL- $88 \mathrm{~B}(\mathrm{Fe})$ is a well-suited host matrix for the encapsulation of antibiofilm compounds. High loadings (about 20 wt \%) of IMI on MIL- $88 \mathrm{~B}(\mathrm{Fe})$ and MIL- $88 \mathrm{~B}(\mathrm{Fe}) \mathrm{PA}$ are possible, and this active molecule could be released when triggered. Although this host matrix is partially degradable by

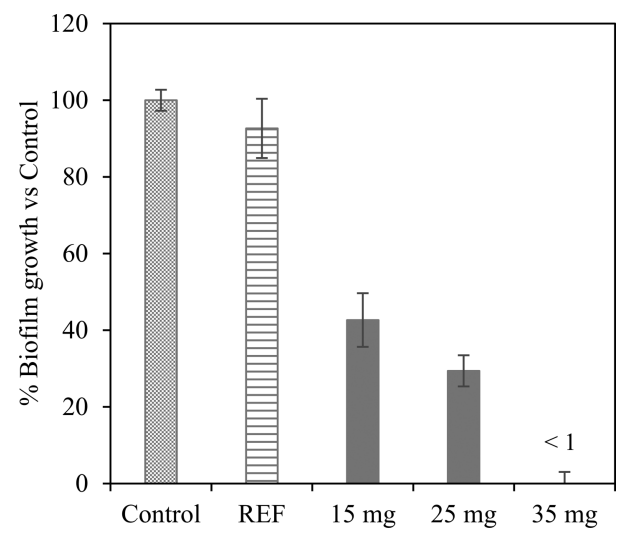

Figure 12. Biofilm inhibition of $S$. Typhimurium ATCC14028 in a Petri dish. As a reference (REF), biofilm is grown on a MOF coating without antibiofilm compound. Biofilm growth is evaluated on different amounts of MIL-88B(Fe) loaded with 10 wt \% IMI. \% Biofilm is calculated in function of biofilm growth on an uncoated control dish. The error bars indicate the positive standard deviation of three technical repeats.

external chelators, it is stable in water and TSB $1 / 20$ medium. After immersion in a chelator-containing solution, iron(III) is released and degradation of MOF crystals is visible with SEM after addition of $10 \mathrm{mM} \mathrm{Na}_{3}$ citrate in water. Besides the decomposition of part of the crystals, the overall crystal structure of the MOF is retained. An additional amount of the antibiofilm compound is released by low concentrations of chelator. Chelators form complexes with the metal ions from the junctions of the host matrix and as such the degradation of the material is triggered due to metal-anion competitive complexation. MIL- $88 \mathrm{~B}(\mathrm{Fe})$ loaded with $10 \mathrm{wt} \% \mathrm{IMI}$ is well attached to the polystyrene surface and inhibits Salmonella biofilm growth by $61 \%$ compared to the reference coating, whereas MIL-88B(Fe)PA coatings with $10 \mathrm{wt} \% \mathrm{IMI}$ are only able to inhibit biofilm growth after addition of an external chelator. In this proof-of-concept study, antibiofilm compounds are released from a host matrix which is partially degraded by chelators. The stimulus-responsive MOF coating is a nontoxic and biocompatible host matrix and will prevent biofouling in an efficient way. For future applications of these antibiofilm coatings in pipelines, (food) industry, agriculture, or medicine, further optimization steps can be performed to enhance their resistance against strong liquid flow or cleaning and rubbing procedures. Moreover, because the activity spectrum of the imidazoles is dependent on their substitution pattern, different imidazole derivatives can be incorporated in order to target biofilm growth of different bacterial strains. Indeed, as the production of siderophores by different bacterial strains is widespread, the concept can likely be transferred to other biofilm forming species.

\section{ASSOCIATED CONTENT}

\section{S Supporting Information}

The Supporting Information is available free of charge on the ACS Publications website at DOI: 10.1021/acsami.6b14152.

Elemental analysis (PDF)

\section{AUTHOR INFORMATION}

\section{Corresponding Author}

*E-mail: dirk.devos@kuleuven.be. 


\section{ORCID 중}

Birgit Claes: 0000-0002-8851-0739

\section{Present Address}

†Centre for Surface Chemistry and Catalysis, KU Leuven, Celestijnenlaan 200F Box 2461, 3001 Leuven, Belgium

\section{Author Contributions}

All authors have given approval to the final version of the manuscript.

\section{Notes}

The authors declare no competing financial interest.

\section{ACKNOWLEDGMENTS}

D.E.D.V. acknowledges the FWO Vlaanderen (Grant Nos. G.0256.14, G.0959.13) for support in the frame of research projects and the Belgian Science Policy Office Interuniversity Attraction Poles (IAP) programme in the frame of IAP 7/05 for financial support. D.E.D.V. also thanks IWT Vlaanderen for support in the SBO program MOFShape. This work was supported by the Research Fund of the KU Leuven under grant BOF-IDO/11/008 and the IWT Flanders under the grant agreement SBO NEMOA (IWT-SBO 120050). H.S. acknowledges the receipt of a postdoctoral fellowship from FWOVlaanderen. G.H. acknowledges the receipt of a doctoral fellowship from the IWT-Vlaanderen. We want to thank Kai Waldrant, David De Coster, and Ami De Weerdt for excellent technical assistance.

\section{ABBREVIATIONS}

MOF, metal-organic framework

MIL, Materials from Institut Lavoisier

IMI, 5-(4-chlorophenyl)- $N$-(2-isobutyl)-2-aminoimidazole

DMF, N,N-dimethylformamide

PA, palmitic acid

PXRD, powder X-ray diffraction

SEM, scanning electron microscopy

UV-vis, Ultraviolet-visible

DRS, diffuse reflectance spectroscopy

TSB, tryptic soy broth

ICP-AES, inductively coupled plasma atomic emission spectroscopy

CFU, colony forming units

CIF, crystallographic information file

CCDC, Cambridge Crystallographic Data Centre

CUS, coordinatively unsaturated sites

$\mathrm{BIC}_{50}$, half maximal biofilm inhibitory concentration

\section{REFERENCES}

(1) Brandt, P.; Brimah, A. K.; Fischer, R. D. Partially Reversible Intercalation of Ferrocene in a Zeolite-like Host Lattice Consisting of $\mathrm{Fe}(\mathrm{CN})_{6}$ and $\mathrm{Me}_{3} \mathrm{Sn}$ Units. Angew. Chem., Int. Ed. Engl. 1988, 27 (11), $1521-1522$.

(2) Hoskins, B. F.; Robson, R. Infinite Polymeric Frameworks Consisting of Three Dimensionally Linked Rod-like Segments. J. Am. Chem. Soc. 1989, 111, 5962-5964.

(3) Hoskins, B. F.; Robson, R. Design and Construction of a New Class of Scaffolding-like Materials Comprising Infinite Polymeric Frameworks of 3D-Linked Molecular Rods. A Reappraisal of the $\mathrm{Zn}(\mathrm{CN})_{2}$ and $\mathrm{Cd}(\mathrm{CN})_{2}$ Structures and the Synthesis and Structure of the Diamond-Related Framework. J. Am. Chem. Soc. 1990, 112, 15461554.

(4) De Munno, B. G.; Julve, M.; Nicolo, F.; Lloret, F.; Faus, J.; Ruiz, R.; Sinn, E. 2,2'-Bipyrimidineoxalatocopper(II) Complexes: From the
Mononuclear Complex to the 2D Sheetlike Polymer. Angew. Chem., Int. Ed. Engl. 1993, 32 (4), 613-615.

(5) Eddaoudi, M.; Kim, J.; Rosi, N.; Vodak, D.; Wachter, J.; O’Keeffe, M.; Yaghi, O. M. Systematic Design of Pore Size and Functionality in Isoreticular MOFs and Their Application in Methane Storage. Science 2002, 295 (5554), 469-472.

(6) Kitagawa, S.; Kitaura, R.; Noro, S. Functional Porous Coordination Polymers. Angew. Chem., Int. Ed. 2004, 43 (18), 2334-2375.

(7) Horcajada, P.; Serre, C.; Maurin, G.; Ramsahye, N. A.; Balas, F.; Vallet-Regí, M.; Sebban, M.; Taulelle, F.; Férey, G. Flexible Porous Metal-Organic Frameworks for a Controlled Drug Delivery. J. Am. Chem. Soc. 2008, 130 (21), 6774-6780.

(8) Furukawa, H.; Cordova, K. E.; O’Keeffe, M.; Yaghi, O. M. The Chemistry and Applications of Metal-Organic Frameworks. Science 2013, 341 (6149), 1230444.

(9) Morris, R. E.; Wheatley, P. S. Gas Storage in Nanoporous Materials. Angew. Chem., Int. Ed. 2008, 47 (27), 4966-4981.

(10) Rosi, N. L.; Eckert, J.; Eddaoudi, M.; Vodak, D. T.; Kim, J.; O’Keeffe, M.; Yaghi, O. M. Hydrogen Storage in Microporous MetalOrganic Frameworks. Science 2003, 300 (5622), 1127-1129.

(11) Li, J.-R.; Kuppler, R. J.; Zhou, H.-C. Selective Gas Adsorption and Separation in Metal-Organic Frameworks. Chem. Soc. Rev. 2009, 38 (5), 1477-1504.

(12) Lee, J.; Farha, O. K.; Roberts, J.; Scheidt, K. A.; Nguyen, S. T.; Hupp, J. T. Metal-Organic Framework Materials as Catalysts. Chem. Soc. Rev. 2009, 38 (5), 1450-1459.

(13) Horcajada, P.; Chalati, T.; Serre, C.; Gillet, B.; Sebrie, C.; Baati, T.; Eubank, J. F.; Heurtaux, D.; Clayette, P.; Kreuz, C.; Chang, J.-S.; Hwang, Y. K.; Marsaud, V.; Bories, P.-N.; Cynober, L.; Gil, S.; Férey, G.; Couvreur, P.; Gref, R. Porous Metal-Organic-Framework Nanoscale Carriers as a Potential Platform for Drug Delivery and Imaging. Nat. Mater. 2010, 9 (2), 172-178.

(14) Schneemann, A.; Bon, V.; Schwedler, I.; Senkovska, I.; Kaskel, S.; Fischer, R. A. Flexible Metal-Organic Frameworks. Chem. Soc. Rev. 2014, 43 (16), 6062-6096.

(15) Taylor-Pashow, K. M. L.; Rocca, J. D.; Xie, Z.; Tran, S.; Lin, W. Postsynthetic Modifications of Iron-Carboxylate Nanoscale MetalOrganic Frameworks for Imaging and Drug Delivery. J. Am. Chem. Soc. 2009, 131 (40), 14261-14263.

(16) Miller, S. R.; Heurtaux, D.; Baati, T.; Horcajada, P.; Grenèche, J.-M.; Serre, C. Biodegradable Therapeutic MOFs for the Delivery of Bioactive Molecules. Chem. Commun. (Cambridge, U. K.) 2010, 46 (25), 4526-4528.

(17) Horcajada, P.; Serre, C.; Vallet-Regí, M.; Sebban, M.; Taulelle, F.; Férey, G. Metal-Organic Frameworks as Efficient Materials for Drug Delivery. Angew. Chem., Int. Ed. 2006, 45 (36), 5974-5978.

(18) An, J.; Geib, S. J.; Rosi, N. L. Cation-Triggered Drug Release from a Porous Zinc-Adeninate Metal-Organic Framework. J. Am. Chem. Soc. 2009, 131 (24), 8376-8377.

(19) Costerton, J. W.; Lewandowski, Z.; Caldwell, D. E.; Korber, D. R.; Lappin-Scott, H. M. Microbial Biofilms. Annu. Rev. Microbiol. 1995, 49, 711-745.

(20) Steenackers, H.; Hermans, K.; Vanderleyden, J.; De Keersmaecker, S. C. J. Salmonella Biofilms: An Overview on Occurrence, Structure, Regulation and Eradication. Food Res. Int. 2012, 45 (2), 502-531.

(21) Donlan, R. M.; Costerton, J. W. Biofilms: Survival Mechanisms of Clinically Relevant Microorganisms. Clin. Microbiol. Rev. 2002, 15 (2), 167-193.

(22) Hall-Stoodley, L.; Stoodley, P. Evolving Concepts in Biofilm Infections. Cell. Microbiol. 2009, 11 (7), 1034-1043.

(23) Steenackers, H. P. L.; Ermolat'ev, D. S.; Savaliya, B.; Weerdt, A.; De Coster, D.; Shah, A.; Van der Eycken, E. V.; De Vos, D. E.; Vanderleyden, J.; De Keersmaecker, S. C. J. Structure-Activity Relationship of 2-Hydroxy-2-Aryl-2,3-Dihydro-imidazo[1,2-A]pyrimidinium Salts and $2 \mathrm{~N}$-Substituted 4(5)-Aryl-2-Amino- $1 \mathrm{H}$-Imidazoles as Inhibitors of Biofilm Formation by Salmonella Typhimurium 
and Pseudomonas aeruginosa. Bioorg. Med. Chem. 2011, 19 (11), 34623473

(24) Høiby, N.; Bjarnsholt, T.; Givskov, M.; Molin, S.; Ciofu, O. Antibiotic Resistance of Bacterial Biofilms. Int. J. Antimicrob. Agents 2010, 35 (4), 322-332.

(25) Banerjee, I.; Pangule, R. C.; Kane, R. S. Antifouling Coatings: Recent Developments in the Design of Surfaces That Prevent Fouling by Proteins, Bacteria, and Marine Organisms. Adv. Mater. 2011, 23 (6), 690-718.

(26) Glinel, K.; Thebault, P.; Humblot, V.; Pradier, C. M.; Jouenne, T. Antibacterial Surfaces Developed from Bio-Inspired Approaches. Acta Biomater. 2012, 8 (5), 1670-1684.

(27) Neoh, K. G.; Kang, E. T. Combating Bacterial Colonization on Metals via Polymer Coatings: Relevance to Marine and Medical Applications. ACS Appl. Mater. Interfaces 2011, 3 (8), 2808-2819.

(28) Rai, M.; Yadav, A.; Gade, A. Silver Nanoparticles as a New Generation of Antimicrobials. Biotechnol. Adv. 2009, 27 (1), 76-83.

(29) Arciola, C. R.; Campoccia, D.; Speziale, P.; Montanaro, L.; Costerton, J. W. Biofilm Formation in Staphylococcus Implant Infections. A Review of Molecular Mechanisms and Implications for Biofilm-Resistant Materials. Biomaterials 2012, 33 (26), 5967-5982.

(30) Shukla, A.; Fleming, K. E.; Chuang, H. F.; Chau, T. M.; Loose, C. R.; Stephanopoulos, G. N.; Hammond, P. T. Controlling the Release of Peptide Antimicrobial Agents from Surfaces. Biomaterials 2010, 31 (8), 2348-2357.

(31) Salwiczek, M.; Qu, Y.; Gardiner, J.; Strugnell, R. A.; Lithgow, T.; McLean, K. M.; Thissen, H. Emerging Rules for Effective Antimicrobial Coatings. Trends Biotechnol. 2014, 32 (2), 82-90.

(32) Van Houdt, R.; Michiels, C. W. Biofilm Formation and the Food Industry, a Focus on the Bacterial Outer Surface. J. Appl. Microbiol. 2010, 109 (4), 1117-1131.

(33) Lu, X.; Ye, J.; Zhang, D.; Xie, R.; Bogale, R. F.; Sun, Y.; Zhao, L.; Zhao, Q.; Ning, G. Silver Carboxylate Metal-Organic Frameworks with Highly Antibacterial Activity and Biocompatibility. J. Inorg. Biochem. 2014, 138, 114-121.

(34) Arpa Sancet, M. P.; Hanke, M.; Wang, Z.; Bauer, S.; Azucena, C.; Arslan, H. K.; Heinle, M.; Gliemann, H.; Wöll, C.; Rosenhahn, A. Surface Anchored Metal-Organic Frameworks as Stimulus Responsive Antifouling Coatings. Biointerphases 2013, 8 (1), 29.

(35) Aguado, S.; Quirós, J.; Canivet, J.; Farrusseng, D.; Boltes, K.; Rosal, R. Antimicrobial Activity of Cobalt Imidazolate Metal-Organic Frameworks. Chemosphere 2014, 113, 188-192.

(36) Steenackers, H. P. L.; Ermolat'ev, D. S.; Savaliya, B.; De Weerdt, A.; De Coster, D.; Shah, A.; Van der Eycken, E. V.; De Vos, D. E.; Vanderleyden, J.; De Keersmaecker, S. C. J. Structure-Activity Relationship of 4(5)-Aryl-2-Amino-1H-Imidazoles, N1-Substituted 2Aminoimidazoles and imidazo[1,2-A]pyrimidinium Salts as Inhibitors of Biofilm Formation by Salmonella Typhimurium and Pseudomonas aeruginosa. J. Med. Chem. 2011, 54 (2), 472-484.

(37) Ermolat'ev, D. S.; Savaliya, B.; Shah, A.; Van der Eycken, E. One-Pot Microwave-Assisted Protocol for the Synthesis of Substituted 2-Amino-1H-Imidazoles. Mol. Diversity 2011, 15 (2), 491-496.

(38) Steenackers, H.; Ermolat'ev, D.; Trang, T. T. T.; Savalia, B.; Sharma, U. K.; De Weerdt, A.; Shah, A.; Vanderleyden, J.; Van der Eycken, E. V. Microwave-Assisted One-Pot Synthesis and Anti-Biofilm Activity of 2-Amino-1H-Imidazole/triazole Conjugates. Org. Biomol. Chem. 2014, 12 (22), 3671.

(39) Robijns, S. C. A.; Roberfroid, S.; Van Puyvelde, S.; De Pauw, B.; Uceda Santamaría, E.; De Weerdt, A.; De Coster, D.; Hermans, K.; De Keersmaecker, S. C. J.; Vanderleyden, J.; Steenackers, H. P. L. A GFP Promoter Fusion Library for the Study of Salmonella Biofilm Formation and the Mode of Action of Biofilm Inhibitors. Biofouling 2014, 30 (5), 605-625.

(40) Allen, R. C.; Popat, R.; Diggle, S. P.; Brown, S. P. Targeting Virulence: Can We Make Evolution-Proof Drugs? Nat. Rev. Microbiol. 2014, 12 (4), 300-308.

(41) Steenackers, H.; Dubey, A.; Robijns, S.; Ermolat'ev, D.; Delattin, N.; Dovgan, B.; Girandon, L.; Fröhlich, M.; De Brucker, K.; Cammue, B. P. A.; Thevissen, K.; Balzarini, J.; Van der Eycken, E. V.;
Vanderleyden, J. Evaluation of the Toxicity of 5-Aryl-2-Aminoimidazole-Based Biofilm Inhibitors against Eukaryotic Cell Lines, Bone Cells and the Nematode Caenorhabditis elegans. Molecules 2014, 19 (10), 16707-16723.

(42) Upritchard, H. G.; Yang, J.; Bremer, P. J.; Lamont, I. L.; McQuillan, A. J. Adsorption of Enterobactin to Metal Oxides and the Role of Siderophores in Bacterial Adhesion to Metals. Langmuir 2011, 27 (17), 10587-10596.

(43) Kuhn, K. M.; DuBois, J. L.; Maurice, P. A. Strategies of Aerobic Microbial $\mathrm{Fe}$ Acquisition from Fe-Bearing Montmorillonite Clay. Geochim. Cosmochim. Acta 2013, 117, 191-202.

(44) Horcajada, P.; Salles, F.; Wuttke, S.; Devic, T.; Heurtaux, D.; Maurin, G.; Vimont, A.; Daturi, M.; David, O.; Magnier, E.; Stock, N.; Filinchuk, Y.; Popov, D.; Riekel, C.; Férey, G.; Serre, C. How Linker's Modification Controls Swelling Properties of Highly Flexible iron(III) Dicarboxylates MIL-88. J. Am. Chem. Soc. 2011, 133 (44), 1783917847.

(45) Deleu, W. P. R.; Rivero, G.; Teixeira, R. F. A.; Du Prez, F. E.; De Vos, D. E. Metal-Organic Frameworks Encapsulated in Photocleavable Capsules for UV-Light Triggered Catalysis. Chem. Mater. 2015, 27 (16), 5495-5502.

(46) Stepanović, S.; Ćirković, I.; Ranin, L.; Švabić-Vlahović, M. Biofilm Formation by Salmonella spp. and Listeria monocytogenes on Plastic Surface. Lett. Appl. Microbiol. 2004, 38 (5), 428-432.

(47) Valdebenito, M.; Crumbliss, A. L.; Winkelmann, G.; Hantke, K Environmental Factors Influence the Production of Enterobactin, Salmochelin, Aerobactin, and Yersiniabactin in Escherichia coli Strain Nissle 1917. Int. J. Med. Microbiol. 2006, 296 (8), 513-520.

(48) Groom, C. R.; Bruno, I. J.; Lightfoot, M. P.; Ward, S. C. The Cambridge Structural Database. Acta Crystallogr., Sect. B: Struct. Sci., Cryst. Eng. Mater. 2016, 72 (2), 171-179.

(49) Dai, J.; McKee, M. L.; Samokhvalov, A. Adsorption of Naphthalene and Indole on F300 MOF in Liquid Phase by the Complementary Spectroscopic, Kinetic and DFT Studies. J. Porous Mater. 2014, 21 (5), 709-727. 